\title{
Early Combination Therapy with Corticosteroid and Nucleoside Analogue Induces Rapid Resolution of Inflammation in Acute Liver Failure due to Transient Hepatitis B Virus Infection
}

\author{
Keiichi Fujiwara ${ }^{1}$, Shin Yasui ${ }^{1}$, Yuuki Haga ${ }^{1}$, Masato Nakamura ${ }^{1}$, Yutaka Yonemitsu ${ }^{1}$, \\ Makoto Arai ${ }^{1}$, Tatsuo Kanda ${ }^{1}$, Shigeto Oda ${ }^{2}$, Osamu Yokosuka ${ }^{1}$ and Naoya Kato ${ }^{1}$
}

\begin{abstract}
:
Objective Patients with acute hepatitis B sometimes develop acute liver failure (ALF), which has a poor prognosis. The efficacy of nucleoside analogue (NA) monotherapy for ALF due to transient hepatitis B virus infection (HBV-ALF) remains controversial. Further investigations are necessary in nations with a shortage of donor livers for liver transplantation. In the present study, we aimed to clarify the efficacy of combination therapy with corticosteroid (CS) and NA in the treatment HBV-ALF.

Patients We examined the clinical and biochemical features of 19 patients with HBV-ALF who were treated in the early stage of the disease between 2000 and 2015.

Results Fourteen patients received CS and NA (CS + NA group) and 5 received NA monotherapy (NA group). Eleven patients (58\%) survived and $8(42 \%)$ died. The survival rates in the CS + NA and NA groups were $64 \%$ and $40 \%$, respectively $(\mathrm{p}=0.60)$. The mean alanine aminotransferase (ALT) levels declined significantly at week 2 in both groups. The mean PT activities improved significantly at weeks 1 and 2 in the CS + NA group $(\mathrm{p}<0.05)$ but not in the NA group. None of the surviving patients developed persistent infection.

Conclusion Combination therapy with CS and NA induces the rapid resolution of inflammation leading to a rapid recovery of the liver function. When it is administered at a sufficiently early stage, it would have a survival benefit and prevent persistent infection in HBV-ALF.
\end{abstract}

Key words: acute hepatitis B, acute liver failure, combination therapy, corticosteroid, nucleoside analogue

(Intern Med 57: 1543-1552, 2018)

(DOI: 10.2169/internalmedicine.9670-17)

\section{Introduction}

It is estimated that more than 2 billion people worldwide have been infected with hepatitis B virus (HBV) (1). Acute hepatitis B (AHB), which is caused by transient HBV infection, sometimes leads to acute liver failure (ALF), which has a poor prognosis (2-4). Mathematical modeling for the year 2,000 estimated that 600,000 deaths from HBV-related disease occurred worldwide, 40,000 were attributed to AHB (5). In contrast to Western countries, AHB accounts for a large proportion of ALF cases in Eastern countries and developing nations (4, 6-9). In Japan, where the government does not provide universal vaccination, it is estimated that 2,100-2,400 people develop AHB per year (17-19 per 1 million population per year); $6 \%$ of these patients develop fulminant hepatitis (FH) and $4 \%$ die of the disease (10). A Japanese nationwide survey also revealed that FH caused by transient HBV infection was associated with a poor prognosis in patients who did not receive liver transplantation (LT) (11). LT, which is the only established treatment for ALF, is often difficult to perform in Japan because of a shortage of donor livers. Thus, treatments other than LT must be further investigated.

${ }^{1}$ Department of Gastroenterology, Graduate School of Medicine, Chiba University, Japan and ${ }^{2}$ Department of Emergency and Critical Care Medicine, Graduate School of Medicine, Chiba University, Japan 
There have been limited studies on the treatment of ALF due to transient HBV infection (HBV-ALF). Nucleoside analogues (NAs) have been shown to markedly suppress HBV replication via the suppression of HBV-polymerase activity; however, the efficacy of these agents in improving the survival of HBV-ALF patients is controversial $(3,4,12)$.

In the United States and Europe, randomized clinical trials in 1970s concluded that corticosteroid (CS) treatment did not enhance the survival of ALF patients, and CS use in ALF has been almost denied (13-15). However, a Japanese nationwide survey revealed that in Japan, where there is a shortage of donor livers, CS treatment was introduced in more than $70 \%$ of ALF cases between 1998 and 2010 for the purpose of suppressing pro-inflammatory cytokines in the early stage of $\operatorname{ALF}(7,8,16,17)$.

We recently reported the efficacy of high-dose CS treatment for suppressing the destruction of hepatocytes in patients with viral ALF, when used in the early stage (18), and also reported the efficacy of high-dose CS in combination with NA for treating severe acute exacerbations in HBV carriers by suppressing HBV DNA rapidly and reversing deterioration, when used in the early stage and for more than a few weeks $(16,19-21)$. However, the efficacy of combination therapy with CS and NA for HBV-ALF is unknown.

In the present study, we aimed to clarify the clinical efficacy of combination therapy with CS and NA for HBV-ALF in comparison to NA monotherapy.

\section{Materials and Methods}

\section{Study design and patients}

This study was a retrospective cohort study in a Japanese tertiary medical facility (Chiba University Hospital). A total of 110 consecutive Japanese adult patients with ALF, who were treated between 2000 and 2015 were enrolled. We analyzed the patients with HBV-ALF who were treated in the early stage. The early stage was defined as a period of $\leq 14$ days after the clinical onset. We divided the patients into two groups according to the treatments: NA and a sufficient dose of CS (combination therapy, CS + NA group) and NA only (monotherapy, NA group). We assessed survival as the primary endpoint and the biochemical response, virological response and complications as secondary endpoints. Patients who had co-infection with hepatitis A virus (HAV), hepatitis $\mathrm{C}$ virus (HCV), or human immunodeficiency virus (HIV) were excluded.

The work described in this manuscript was carried out in accordance with The Code of Ethics of the World Medical Association (Declaration of Helsinki). Informed consent was obtained from all patients or appropriate family members. This study was approved by an institutional review board (2153).

\section{Diagnosis}

The diagnosis of hepatitis $\mathrm{B}$ was made based on the posi- tivity for hepatitis B surface antigen (HBsAg), IgM antihepatitis B core antibodies (IgM-HBc), or HBV DNA. A diagnosis of acute hepatitis B was made based on either negative test result for HBsAg preceding the onset of liver injury in the absence of immunosuppressive and/or anticancer therapies in the previous 12 months, or a positive test for high levels of IgM-HBc and negative or low levels of $\operatorname{IgG}$ anti-hepatitis B core antibodies (22).

The diagnosis of ALF was made based on the diagnostic criteria for ALF in Japan (2011), as follows: a prothrombin time (PT) of $\leq 40 \%$ the standardized value, or an international normalization ratio (INR) of $\geq 1.5$ due to severe liver damage within 8 weeks after the onset of disease symptoms, where the liver function prior to the current onset of liver damage was estimated to have been normal based on blood laboratory data and imaging examinations. ALF is classified into ALF without hepatic coma and ALF with hepatic coma; patients with the former type present no or grade I hepatic encephalopathy, while patients with the latter type show grade $\geq$ II hepatic encephalopathy. ALF with hepatic coma is further subclassified into 2 disease types: the "acute type" and the "subacute type". In the acute type, grade $\geq$ II hepatic encephalopathy develops within 10 days after the onset of disease symptoms; in the subacute type, it develops after 1156 days after the onset of disease symptoms (23).

\section{Virological analysis}

Patients were examined for viral markers including IgMhepatitis A antibodies, IgM-HBc, HBsAg, HBV DNA, $\mathrm{HBeAg}$, anti-HBe antibodies (HBeAb), hepatitis D virus (HDV) RNA, anti-HCV antibodies, HCV RNA, hepatitis E virus (HEV) RNA, IgM anti- Epstein-Barr virus antibodies, IgM anti-Herpes simplex virus antibodies and $\operatorname{IgM}$ anticytomegalovirus antibodies. None of the patients had clinical or laboratory evidence of AIDS.

\section{Treatment}

High-dose CS therapy with $1,000 \mathrm{mg}$ of methylprednisolone (MPSL) or $60 \mathrm{mg}$ of prednisolone (PSL), daily (as the initial dose) was administered. The dose was reduced doses according to the treatment response. NA (lamivudine before 2007, entecavir after 2007) and/or interferon was administered as antiviral therapy, and was stopped after HBsAg clearance. Patients received intravenous glycyrrhizin, an aqueous extract of licorice root, at a daily use of 60-100 $\mathrm{mL}$. This agent is reported to have anti-inflammatory activity and has been used for the treatment of acute and chronic liver injury in Japan $(24,25)$. All patients received comprehensive supportive care, including artificial liver support (plasma exchange and hemodiafiltration) for comatose patients (26).

\section{Assessment}

A biochemical response was defined as the improvement of alanine aminotransferase (ALT), PT activity and total bilirubin (T-BIL) at 1 and 2 weeks after the start of treat- 
Table 1. Clinical Features of All and Each Treatment Groups at Admission.

\begin{tabular}{|c|c|c|c|c|}
\hline & $\begin{array}{l}\text { Overall } \\
(n=19)\end{array}$ & $\begin{array}{c}\text { CS+NA Group } \\
(n=14)\end{array}$ & $\begin{array}{l}\text { NA Group } \\
\quad(n=5)\end{array}$ & $\begin{array}{c}\mathrm{p} \\
(\mathrm{CS}+\mathrm{NA} \text { vs. NA) }\end{array}$ \\
\hline Female sex* & $8(42)$ & $5(36)$ & $3(60)$ & $0.60 \ddagger$ \\
\hline Age $†$ (yr) & $45.0 \pm 14.2$ & $50.0 \pm 9.5$ & $32.0 \pm 18.0$ & $0.06 \S$ \\
\hline \multicolumn{5}{|l|}{ Type of disease* } \\
\hline ALF without coma & $6(32)$ & $5(36)$ & $1(20)$ & $1.00 \ddagger$ \\
\hline ALF with coma & $13(68)$ & $9(64)$ & $4(80)$ & - \\
\hline Acute type & $11(58)$ & $8(57)$ & $3(60)$ & $1.00 \ddagger$ \\
\hline Subacute type & $2(10)$ & $1(7)$ & $1(20)$ & - \\
\hline \multicolumn{5}{|l|}{ Laboratory values $\dagger$} \\
\hline AST (IU/L) & $7,145 \pm 7,651$ & $7,532 \pm 8,183$ & $6,060 \pm 6,618$ & $0.58 \S$ \\
\hline ALT (IU/L) & $6,309 \pm 4,136$ & $6,625 \pm 4,217$ & $5,424 \pm 4,226$ & $0.55 \S$ \\
\hline LDH (IU/L) & $5,143 \pm 8,603$ & $5,683 \pm 9,768$ & $3,631 \pm 4,367$ & $0.52 \S$ \\
\hline T-BIL (mg/dL) & $8.6 \pm 4.8$ & $7.5 \pm 3.0$ & $11.7 \pm 7.5$ & $0.13 \S$ \\
\hline D-BIL (mg/dL) & $5.5 \pm 4.3$ & $4.9 \pm 2.0$ & $7.3 \pm 6.2$ & $0.49 \S$ \\
\hline $\mathrm{PT}(\%)$ & $18 \pm 16$ & $20 \pm 17$ & $14 \pm 13$ & $0.46 \S$ \\
\hline PLT $(\times 10,000 / \mu \mathrm{L})$ & $13.3 \pm 8.7$ & $12.4 \pm 8.2$ & $15.9 \pm 10.4$ & $0.49 \S$ \\
\hline Cre (mg/dL) & $1.5 \pm 1.3$ & $1.5 \pm 1.3$ & $1.6 \pm 1.6$ & $0.40 \S$ \\
\hline $\operatorname{AFP}(n g / m L)$ & $117 \pm 274$ & $113 \pm 306$ & $128 \pm 177$ & $0.31 \S$ \\
\hline HGF (ng/mL) & $5.8 \pm 7.1$ & $5.1 \pm 7.3$ & $7.8 \pm 7.0$ & $0.40 \S$ \\
\hline
\end{tabular}

CS: corticosteroid, NA: nucleoside analogue, AST: aspartate aminotransferase, ALT: alanine aminotranferase, LDH: lactate dehydrogenase, T-BIL: total bilirubin, D-BIL: direct bilirubin, PT: prothrombin time, PLT: platelet, Cre: creatinine, AFP: alpha-fetoprotein, HGF: hepatocyte growth factor

* No. $(\%), \nmid$ mean \pm SD, $¥$ Fisher’s exact probability test, §Wilcoxon rank sum test

ment. A virological response was defined as the decline of HBV DNA at 2 weeks after treatment and HBsAg seroconversion. HBsAg seroconversion was defined as serum HBsAg clearance and the presence of anti-HBs antibodies (HBsAb).

\section{Statistical analysis}

We analyzed the differences in variables between groups and the differences in of HBV DNA changes by Fisher's exact probability test, Pearson's chi-squared test, the Wilcoxon rank sum test or Student's $t$-test using the SPSS software program (version 22, IBM, New York, USA), and analyzed differences in the changes in the ALT level, PT activity and T-BIL level by the Friedman test and Dunn's multiple comparison test using the GraphPad Prism 5 software program (version 5.0a, GraphPad software, La Jolla, USA). p values of $<0.05$ were considered to indicate statistical significance.

\section{Results}

\section{Patients and treatment}

Among the 110 patients, 23 patients with HBV-ALF were admitted to our unit during the study period. Four patients were excluded because the period from the onset of clinical symptoms was $>14$ days or because they were not treated sufficiently; thus, 19 patients were included in this study. None of the patients had co-infection with HAV, HCV or HIV. The mean age of the 19 patients was $45.0 \pm 14.2$ years, and 8 patients were female. Fourteen patients received com- bination therapy with CS and NA (CS + NA group) and 5 received NA monotherapy (NA group) (Table 1).

As the initial CS treatment, PSL $(60 \mathrm{mg})$ was administered to the first patient in 2002; MPSL (1,000 mg) was administered to the 13 subsequent patients. The mean duration between the onset and the introduction of CS was 4.6 \pm 2.4 days, the mean period of CS therapy was 7.3 \pm 5.5 (mean \pm $\mathrm{SD}$ ) days and the mean total dose of CS was $4.1 \pm 1.0 \mathrm{~g}$. NA was administered to all patients; entecavir (ETV) to 9 patients in the CS + NA group, lamivdine (LMV) to 5 patients in the CS + NA group and 5 patients in the NA group. Interferon was administered to 2 patients in the CS + NA group and to 1 patient in the NA group. The mean duration between the onset and the introduction of NA was 5.5 \pm 3.1 days and the mean period of NA therapy was $51.7 \pm 39.6$ days.

\section{The clinical and virological features at admission}

Table 1 shows the clinical features of patients at admission. There were no differences in the age, sex, type of disease or laboratory values between the CS + NA group and the NA group at admission. There were no statistically significant differences between the two groups.

Table 2 shows the virological features (HBV DNA, the HBV genotypes, precore mutations, core promoter mutations, and the number of cases that were positive for $\mathrm{HBsAg}, \mathrm{HBsAb}, \mathrm{HBeAg}$ and $\mathrm{HBeAb}$ ) at admission. There were no statistically significant differences between the two groups. 
Table 2. Virological Features of All and Each Treatment Groups at Admission.

\begin{tabular}{lcccc}
\hline & $\begin{array}{c}\text { Overall } \\
(\mathrm{n}=19)\end{array}$ & $\begin{array}{c}\text { CS+NA Group } \\
(\mathrm{n}=14)\end{array}$ & $\begin{array}{c}\text { NA Group } \\
(\mathrm{n}=5)\end{array}$ & $\begin{array}{c}\mathrm{p} \\
(\mathrm{CS}+\mathrm{NA} \text { vs. NA })\end{array}$ \\
\hline HBV DNA $\dagger($ log copies/mL) & $5.3 \pm 1.3$ & $5.3 \pm 1.5$ & $5.2 \pm 0.8$ & $0.63 \ddagger$ \\
Genotype of HBV* & & & & \\
A & $2(11)$ & $0(0)$ & $2(40)$ & $0.053 \S$ \\
B & $2(11)$ & $2(14)$ & $0(0)$ & \\
C & $4(21)$ & $4(29)$ & $0(0)$ & \\
Not determined & $3(16)$ & $3(21)$ & $0(0)$ & \\
No data & $8(42)$ & $5(36)$ & $3(60)$ & $0.07 \S$ \\
Precore mutation* & & & & \\
Wild & $3(16)$ & $1(7)$ & $2(20)$ & $0.52 \S$ \\
Mutant & $7(37)$ & $7(50)$ & $0(0)$ & \\
No data & $9(47)$ & $6(43)$ & $3(60)$ & \\
Core promoter mutation* & & & & \\
Wild & $7(37)$ & $5(36)$ & $2(40)$ & \\
Mutant & $3(16)$ & $3(21)$ & $0(0)$ & \\
No data & $9(47)$ & $6(43)$ & $3(60)$ & \\
HBs antigen/antibody* & & & & \\
positive/negative & $13(68)$ & $9(64)$ & $4(80)$ & \\
positive/positive & $4(21)$ & $4(29)$ & $0(0)$ & \\
negative/positive & $2(11)$ & $1(7)$ & $1(20)$ & \\
HBe antigen/antibody* & & & & \\
positive/negative & $4(21)$ & $3(21)$ & $1(20)$ & \\
positive/positive & $5(26)$ & $4(29)$ & $1(20)$ & \\
negative/positive & $10(53)$ & $7(50)$ & $3(60)$ & \\
\hline
\end{tabular}

CS: corticosteroid, NA: nucleoside analogue, HBs antigen/antibody: hepatitis B surface antigen/antibody, HBe antigen/antibody: hepatitis B envelope antigen/antibody

$*$ No. $(\%), \dagger$ mean \pm SD, $\neq$ Wilcoxon rank sum test, $\S$ Pearson’s chi-square test

\section{Outcome}

Eleven of the $19(58 \%)$ patients survived and $8(42 \%)$ died due to liver failure. None of the patients received liver transplantation. The overall survival rates were $64 \%$ in the $\mathrm{CS}+\mathrm{NA}$ group and $40 \%$ in the NA group $(\mathrm{p}=0.60)$. The survival rates in patients with acute-type ALF with coma were $44 \%$ in the CS + NA group and $25 \%$ in the NA group $(\mathrm{p}=1.00)$.

\section{Biochemical responses}

Fig. 1a, b and c show the changes in the ALT levels, PT activities and T-BIL levels after the start of treatment, respectively. The mean ALT levels declined significantly at week 1 in the CS + NA group and at week 2 in both groups. The mean PT activities showed a significant improvement at week 1 and 2 in the CS + NA group but not in the NA group. The mean T-BIL levels showed no significant changes at weeks 1 or 2 in either group.

\section{Virological responses}

Fig. 1d shows the change in HBV DNA load. The Mean HBV DNA levels declined significantly at week 2 in the CS + NA group. In the NA group, HBV DNA was only measured in 2 patients at week 2; thus, it was not possible to conduct a statistical analysis.
Regarding HBV DNA and HBsAg clearance after the start of treatment, 8 of the 9 surviving patients in the CS + NA group had been positive for HBsAg before treatment; 6 patients ( 2 were lost to follow-up) achieved HBsAg seroconversion without HBV DNA. All of the surviving patients in the NA group were positive for HBsAg before treatment, and all patients achieved $\mathrm{HBsAg}$ seroconversion without HBV DNA. NA use was stopped after HBsAg clearance, and no patients developed $\mathrm{HBV}$ reactivation during the follow-up period: the median interquartile range (IQR) was 715 days (112-1,824) in the CS + NA group, and 85 and 503 days in the NA group. The mean HBsAb titer at the time of stopping NA was $71.6 \pm 89.5 \mathrm{mIU} / \mathrm{mL}$.

\section{Complications}

The complications at admission in the CS + NA group included acute renal failure $(n=2)$, acute pancreatitis $(n=1)$, and hyperamylasemia $(n=1)$. The complications after admission included gastrointestinal hemorrhage $(n=2)$, hemorrhage of the iliopsoas and rectus abdominis muscle $(n=1)$, catheter-related blood stream infection $(n=1)$, and aspergillus pneumonia $(n=1)$. In the NA group, 1 patient had acute renal failure and was pregnant (third trimester) at admission. No patients had complications after admission. There were no differences in the incidence of complications at admission $(\mathrm{p}=1.00)$ or after admission $(\mathrm{p}=0.24)$. 

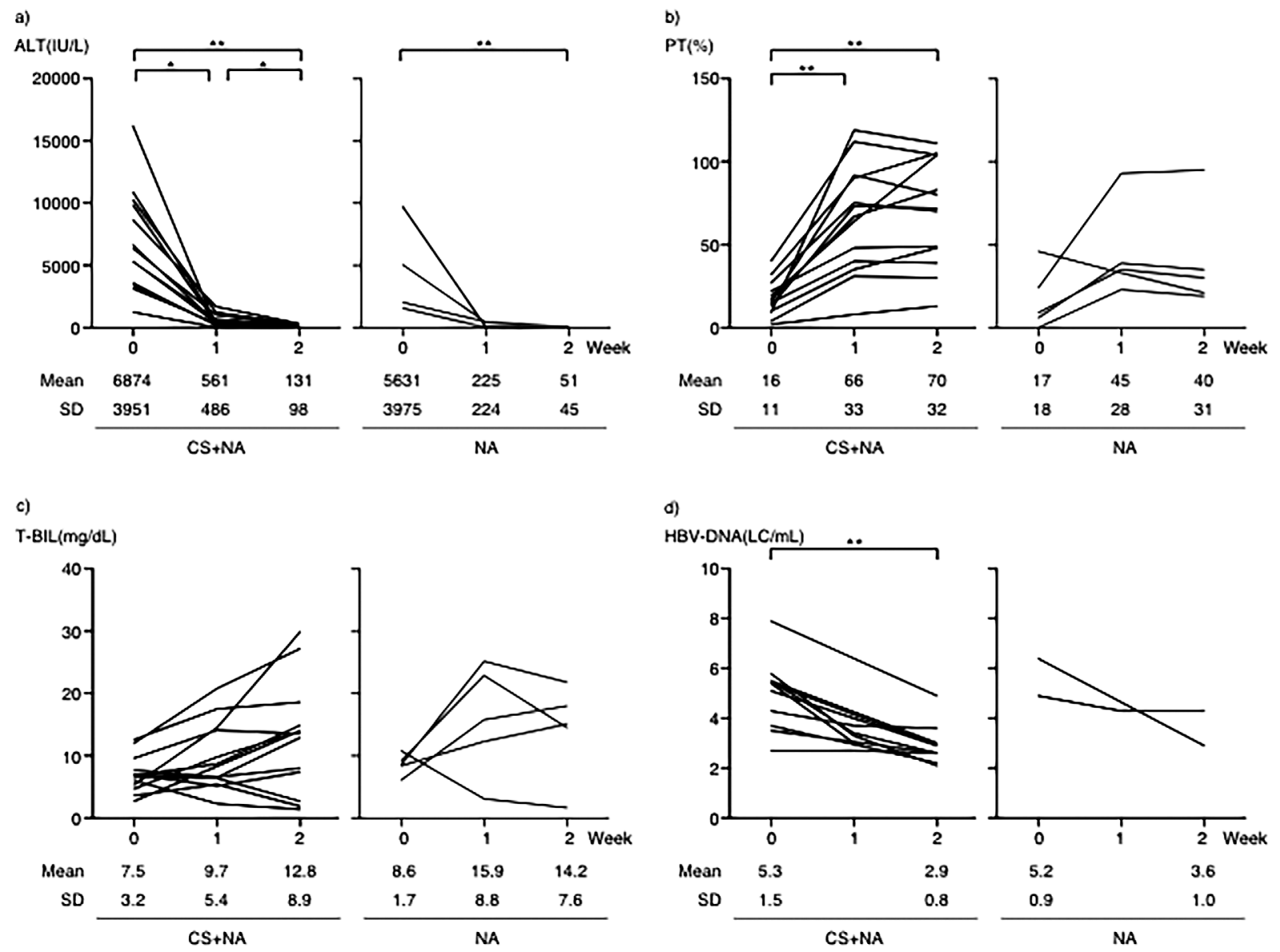

Figure 1. Changes in alanine aminotransferase (ALT) (a), prothrombin time (PT) (b), total bilirubin (T-BIL) (c), and HBV DNA level (d) in the CS+NA and NA group; *p<0.05, **p<0.01.

\section{Comparison between the survivors and the non- survivors}

There were no statistically significant differences in sex, or the mean levels of aspartate aminotransferase (AST), ALT, lactate dehydrogenase (LDH), D-BIL, platelet (PLT), alpha-fetoprotein (AFP), hepatocyte growth factor (HGF) or HBV DNA between the survivors and the non-survivors. The non-survivors had a higher proportion of patients with ALF with coma $(\mathrm{p}=0.01)$. The mean age, T-BIL level and Cre level were higher $(p=0.03,0.03$ and 0.02 , respectively), and mean PT activity was lower $(\mathrm{p}=0.03)$ in the nonsurvivors (Table 3 ).

Fig. 2 show changes in the ALT level, PT activity, T-BIL level and HBV DNA load after the start of treatment in both groups, respectively. The mean ALT level declined significantly at week 2 in both groups ( $p<0.001$, respectively). The mean PT activity showed a significant improvement at weeks 1 and 2 in the survivors $(\mathrm{p}<0.001$ and $\mathrm{p}<0.01$, respectively). The mean T-BIL level was significantly elevated at weeks 1 and 2 in non-survivors $(\mathrm{p}<0.05$ and $\mathrm{p}<0.01$, respectively). The mean HBV DNA level showed a significant decline at week 2 in the survivors $(\mathrm{p}<0.01)$.

\section{Discussion}

The present study showed two important clinical observations. First, although the result did not reach statistical significance, combination therapy with NA and CS led to the rapid recovery of the liver function, and as a result, a higher survival rate than NA monotherapy in patients with HBVALF. Second, combination therapy achieved HBsAg seroconversion with HBV DNA negativity, and NA could be stopped safely without the reactivation of HBV DNA in survivors. The clinical course of a recovered patient is shown in Fig. 3.

The efficacy of NA monotherapy in the treatment of HBV-ALF remains controversial. Earlier studies reported a survival benefit $(12,27,28)$. In contrast, a recent large cohort study reported that NA therapy did not show a survival benefit in patients with HBV-related ALF, including acute HBV-ALF, because patients did not benefit from viral suppression using NA due to the rapid evolution of the disease and the short duration of treatment (4).

In the present study, the spontaneous survival rate (survival rate without LT) of HBV-ALF patients was 58\% (11/ 19). According to the type of therapy, the survival rate in the CS + NA group was $64 \%(9 / 14)$, while that in the NA 
Table 3. Clinical Features of Survived and Dead Patients at Admission.

\begin{tabular}{|c|c|c|c|}
\hline & $\begin{array}{l}\text { Survived } \\
(\mathrm{n}=11)\end{array}$ & $\begin{array}{l}\text { Dead } \\
(n=8)\end{array}$ & $\mathrm{p}$ \\
\hline Female sex $*$ & $7(64)$ & $1(13)$ & $0.63 \neq$ \\
\hline Age $\dagger(y r)$ & \pm & $46.9 \pm 13.2$ & $0.03 \S$ \\
\hline \multicolumn{4}{|l|}{ Type of disease* } \\
\hline ALF without coma & $6(55)$ & $0(0)$ & $0.01 \div$ \\
\hline ALF with coma & $5(45)$ & $8(100)$ & \\
\hline Acute type & $5(45)$ & $6(75)$ & $0.35 \neq$ \\
\hline Subacute type & $0(0)$ & $2(25)$ & \\
\hline \multicolumn{4}{|l|}{ Laboratory values $\dagger$} \\
\hline AST (IU/L) & $5,361 \pm 4,778$ & $9,598 \pm 10,297$ & $0.24 \S$ \\
\hline ALT (IU/L) & $5,252 \pm 3,541$ & $7,763 \pm 4,681$ & $0.20 \S$ \\
\hline LDH (IU/L) & $2,902 \pm 2,906$ & $8,224 \pm 12,629$ & $0.19 \S$ \\
\hline T-BIL (mg/dL) & $6.6 \pm 1.9$ & $11.4 \pm 6.2$ & $0.03 \S$ \\
\hline D-BIL (mg/dL) & $4.4 \pm 1.5$ & $7.1 \pm 4.9$ & $0.11 \S$ \\
\hline $\mathrm{PT}(\%)$ & $25 \pm 16$ & $9 \pm 10$ & $0.03 \S$ \\
\hline PLT $(\times 10,000 / \mu \mathrm{L})$ & $14.9 \pm 8.8$ & $11.2 \pm 8.6$ & $0.38 \S$ \\
\hline Cre $(\mathrm{mg} / \mathrm{dL})$ & $0.9 \pm 0.8$ & $2.4 \pm 1.6$ & $0.02 \S$ \\
\hline $\mathrm{AFP}(\mathrm{ng} / \mathrm{mL})$ & $180 \pm 347$ & $30 \pm 73$ & $0.19 \S$ \\
\hline $\mathrm{HGF}(\mathrm{ng} / \mathrm{mL})$ & $5.3 \pm 7.7$ & $6.4 \pm 6.8$ & $0.78 \S$ \\
\hline HBV DNA (log copies/mL) & $5.3 \pm 1.6$ & $5.3 \pm 1.0$ & $0.97 \S$ \\
\hline \multicolumn{4}{|c|}{$\begin{array}{l}\text { AST: aspartate aminotransferase, ALT: alanine aminotranferase, LDH: lactate dehy- } \\
\text { drogenase, T-BIL: total bilirubin, D-BIL: direct bilirubin, PT: prothrombin time, } \\
\text { PLT: platelet, Cre: creatinine, AFP: alpha-fetoprotein, HGF: hepatocyte growth fac- } \\
\text { tor }\end{array}$} \\
\hline
\end{tabular}

group was $40 \%(2 / 5)$.

The published studies on the efficacy of NA in HBV-ALF in studies that involve $\geq 10$ patients are summarized in Table 4. Dao and the US-Acute Liver Failure (ALF) Study Group reported that the rate of spontaneous survival of HBV-ALF patients treated with NA was $22 \%(6 / 27)(4)$, which was inferior to the survival rate of our overall population and the CS + NA group $(\mathrm{p}=0.015$ and $\mathrm{p}=0.011$, respectively). Yu et al. evaluated the efficacy of LMV in patients with fulminant hepatitis B (3). They also performed pulse steroid treatment with MPSL (500-1,000 mg/day) for 3 days in order to suppress the activity of liver injury according to the description of their treatment protocol, and showed that the spontaneous survival of Chinese fulminant hepatitis patients treated with LMV and CS was 37\% (14/38); this result was not significantly different from the survival rate of our CS + NA-treated fulminant hepatitis patients $(\mathrm{p}=0.48)$.

Tillmann et al. (12) and Kumar et al. (29) reported high survival rates, probably because the proportions of fulminant hepatitis patients were much smaller than in other studies. Miyake et al. also reported a survival rate of $70 \%(7 / 10)$ in fulminant hepatitis patients (30), probably because their patients had less advanced disease: 70\% had coma grade II, and some had received pulse steroid treatment. A Japanese nationwide survey conducted between 1998 and 2009 revealed that the spontaneous survival rate of HBV-ALF patients was $49.8 \%(8,11)$.

Webster et al. observed that the initial and maximal re- duction in HBV DNA occurred before the peak of ALT, and that adaptive immune mechanisms are present during the incubation phase (31). The incubation phase, including the early clinical phase before the ALT peak could be considered as the critical period for the interaction between the host and HBV. Thus, we believe that rapid immunosuppression in the early clinical phase, especially before the ALT peak, is important for the cessation of the massive destruction of hepatocytes, which leads to recovery from liver failure.

The use of CS in ALF was denied in the US and European countries in the 1970s, as describe above. However, the results that led to this position were premature because CS was not administered in a uniform fashion, especially with regard to the timing of administration. Subsequently, the mechanisms of ALF came to be understood: massive hepatic necrosis triggers an innate immune response, which is followed by inflammatory cell recruitment, which exacerbates the initial liver injury, and pro-inflammatory cytokines predominate at an early phase. CSs are known to suppress proinflammatory genes and induce anti-inflammatory genes. Thus, CS treatment might be beneficial during the early phase of ALF (32). Now that effective agents against the complications that occur due to CS treatment (i.e., antibacterial, anti-fungal, and anti-viral agents, $\mathrm{H}_{2}$-blockers/proton pump inhibitors) have become available, the efficacy of CS treatment for ALF should be re-evaluated.

We have previously reported the benefit of combination 
a)

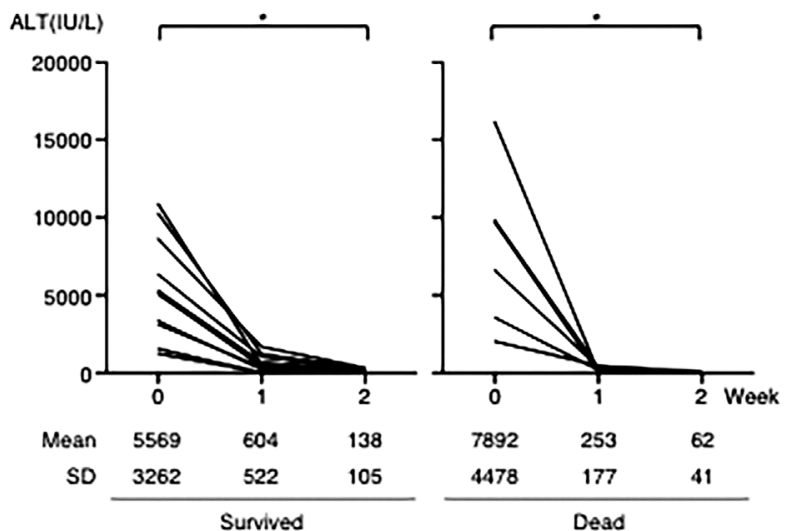

c)

T.BIL $(\mathrm{mg} / \mathrm{dL})$
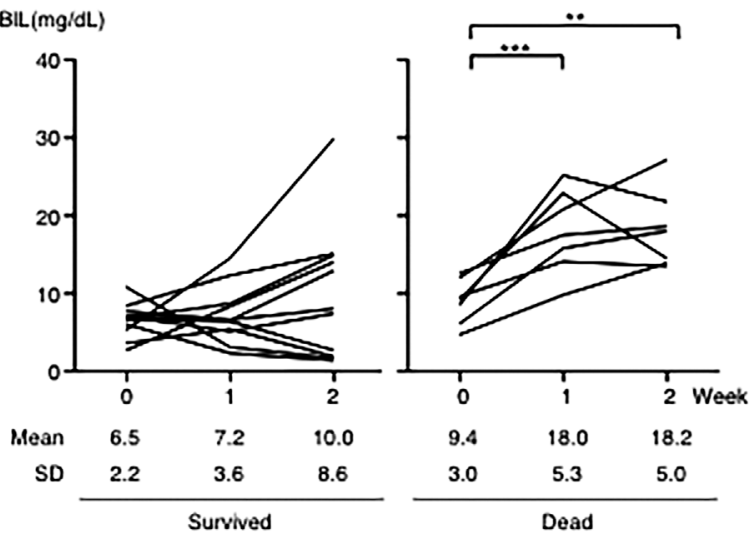

b)

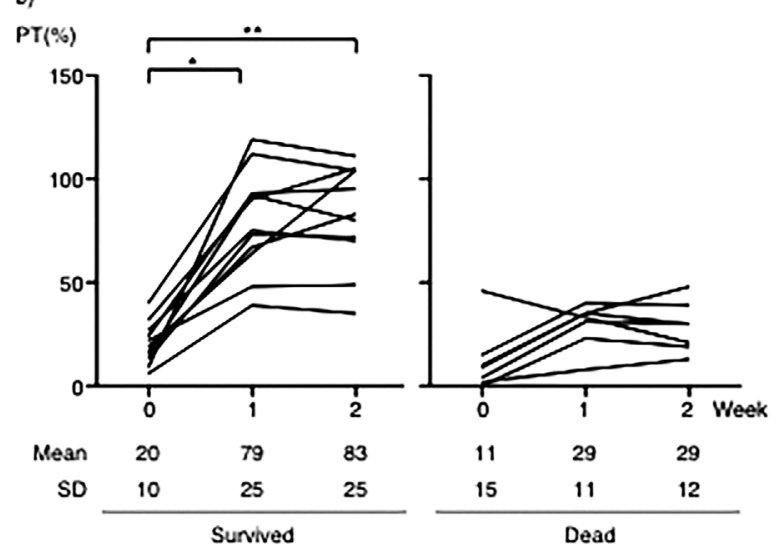

d)

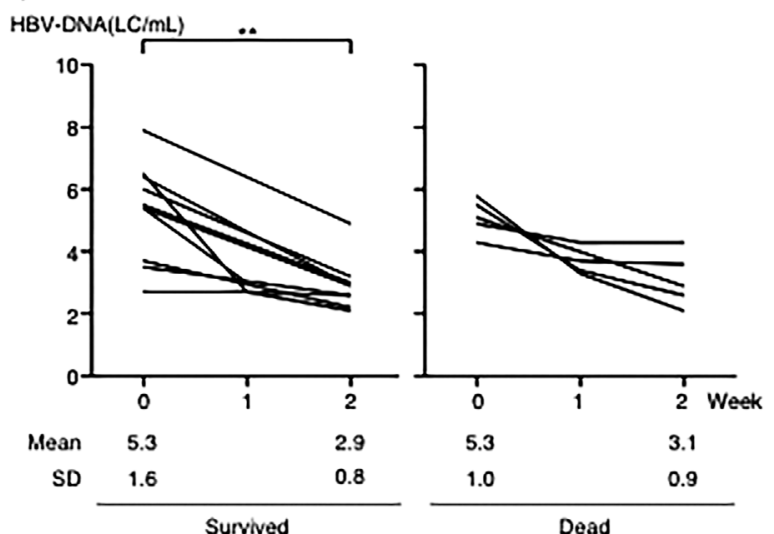

Figure 2. Changes in alanine aminotransferase (ALT) (a), prothrombin time (PT) (b), total bilirubin (T-BIL) (c), and HBV DNA level (d) in survivors and non-survivors; *p<0.001, **p<0.01, $* * * \mathbf{p}<\mathbf{0 . 0 5}$.

therapy with high-dose CS and NA in HBV-related ALF (16, 18-21). In the present study, the PT activity of the $\mathrm{CS}+\mathrm{NA}$ group recovered more rapidly in comparison to the NA group, which indicates that rapid immunosuppression with high-dose CS induced rapid liver regeneration. The high transaminase level and low PT activity of our patients at admission suggest that the massive destruction of hepatocytes in the whole liver was ongoing; thus, the administration of high-dose CS in the early clinical stage would be reasonable for controlling the liver enzyme levels, and suppressing liver inflammation and the progression of liver failure.

Combination therapy with CS and NA achieved the clearance of HBsAg with HBV DNA negativity. CS therapy is generally considered to be associated with a risk of progression to persistent HBV infection; however, none of our patients who were treated with CS showed this progression. NA in combination with CS might contribute to the prevention of persistent infection. However, recent Japanese studies revealed that $4.2-9.8 \%$ of $\mathrm{AHB}$ patients developed chronic infection and that NA treatment did not prevent progression to chronic infection $(33,34)$. Patients starting NA treatment within 8 weeks from the onset of disease never progressed to chronicity (33). In the present study, the rapid initiation of NA (the median duration from the onset to initiation was 5 days), might lead to the prevention of persistent infection. Additionally, our data suggest that NA can be stopped safely in the presence of $\mathrm{HBsAb}$ without future reactivation.

In the present study, there were no differences in the incidence of complications between the CS + NA and NA groups. However, fungal infection occurred in one patient in the CS + NA group. We previously reported that CS use did not significantly increase the incidence of infection in acute liver failure of various etiologies (35). In that report, fungal infection only occurred in patients treated with CS; however, the difference between the patients with and without CS did not reach statistical significance. Physicians should take care of the possible development of fungal infection, which may occur as a complication of CS. Although peptic ulcer is a major complication of CS, none of the gastrointestinal hemorrhage events that occurred in the present study were due to peptic ulcer.

The present study is associated with some limitations. First, although this is one of the largest case series reported from a single center to date, the number of patients in our study was limited (Table 4). Second, this was not a randomized study because ethical issues obviously prevent a randomized control study due to the life-threatening nature of 


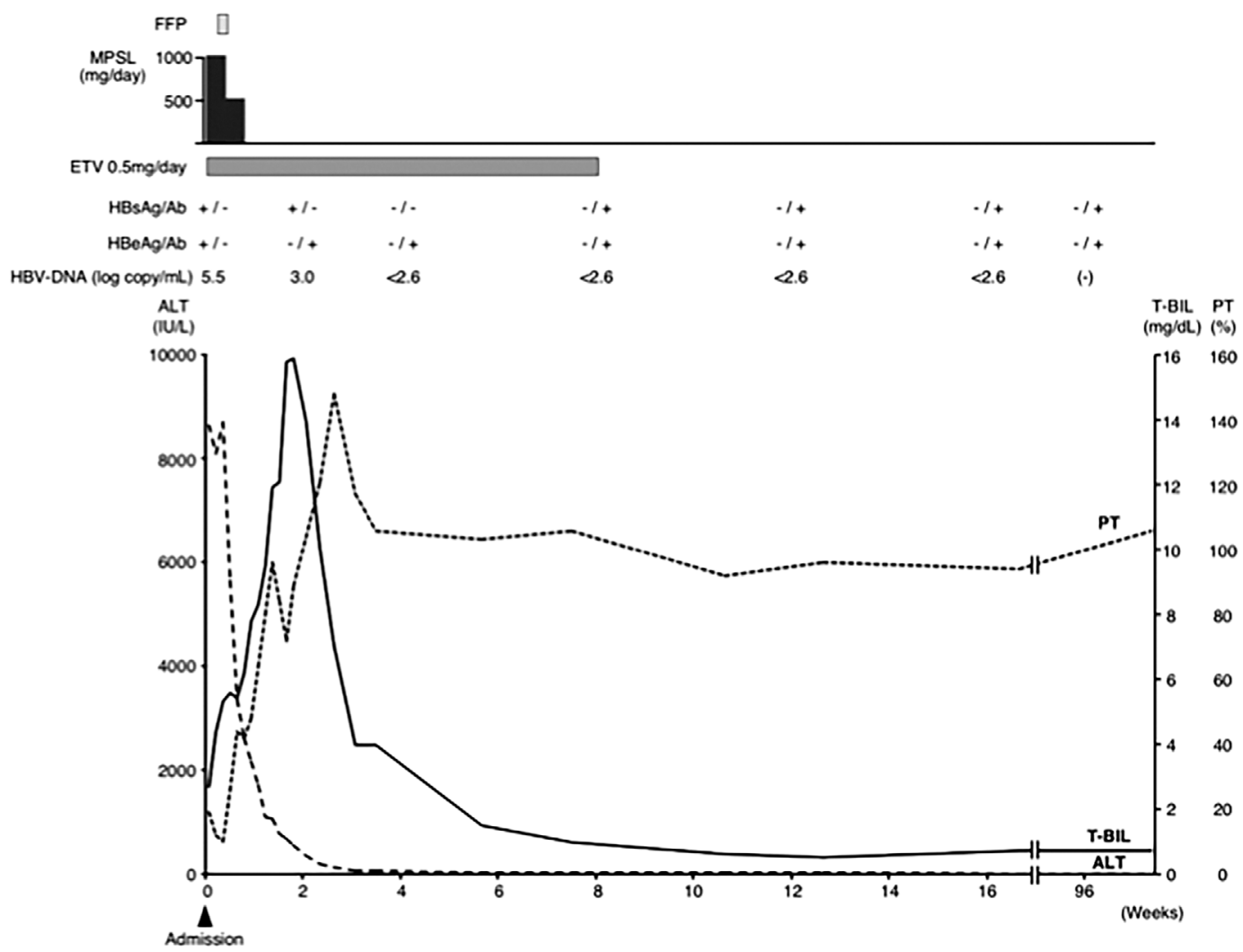

Figure 3. The clinical course of a 37-year-old female patient. She was admitted to our unit at four days after the onset of disease. Corticosteroid was administered in combination with nucleoside analogue. Her ALT levels rapidly decreased, and her PT improved. Her T-BIL levels gradually improved. Nucleoside analogue was administered for 8 weeks until HBs Ag clearance. Liver function tests continued to be normal without $\mathrm{HBV}$ reactivation during the follow-up period of 24 months. FFP: fresh frozen plasma, MPSL: methylpredonisolone, ETV: entecavir, ALT: alanine aminotranferase, T-BIL: total bilirubin, PT: prothrombin time

Table 4. Publications about the Efficacy of NA in HBV-ALF.

\begin{tabular}{|c|c|c|c|c|c|c|}
\hline Reference & 4 & 3 & 12 & 29 & 30 & Present study \\
\hline Inclusion criteria & $\begin{array}{l}\text { ALF } \\
\cdot \text { INR } \geq 1.5 \\
\cdot \text { HE }\end{array}$ & $\begin{array}{l}\mathrm{FHF} \\
\cdot \mathrm{PT} \leq 40 \% \\
\cdot \mathrm{HE} \geq \text { grade II }\end{array}$ & $\begin{array}{l}\text { SH, FH } \\
\cdot \text { INR }>2.0 \\
\cdot \mathrm{HE}^{*}\end{array}$ & $\begin{array}{l}\mathrm{SH}^{* *} \\
\cdot \mathrm{INR} \geq 1.6 \\
\cdot \mathrm{HE} \\
\cdot \mathrm{T}-\mathrm{BIL} \geq \\
10.0 \mathrm{mg} / \mathrm{dL}\end{array}$ & $\begin{array}{l}\mathrm{FH} \\
\cdot \mathrm{PT} \leq 40 \% \\
\cdot \mathrm{HE} \geq \text { grade II }\end{array}$ & $\begin{array}{l}\text { ALF } \\
\cdot \mathrm{PT} \leq 40 \% \text { or } \\
\mathrm{INR} \geq 1.5\end{array}$ \\
\hline $\begin{array}{l}\text { Number of patients } \\
\text { treated with NA } \\
\text { (FH/SH) }\end{array}$ & 27 & $\begin{array}{c}38 \\
(38 / 0)\end{array}$ & $\begin{array}{c}17 \\
(7 / 10)\end{array}$ & $\begin{array}{c}22 \\
(2 / 20)\end{array}$ & $\begin{array}{c}10 \\
(10 / 0)\end{array}$ & $\begin{array}{c}19 \\
(13 / 6)\end{array}$ \\
\hline Type of NA & Not described & LMV 38 & LMV 17 & LMV 22 & LMV 10 & LMV 10 ETV 9 \\
\hline $\begin{array}{l}\text { Number of patients } \\
\text { treated with CS }\end{array}$ & - & 38 & - & - & + & 14 \\
\hline $\begin{array}{l}\text { Transplant-free } \\
\text { survival rate }\end{array}$ & $22 \%$ & $37 \%$ & $82 \%$ & $100 \%$ & $70 \%$ & $58 \%$ \\
\hline Country & United States & China & Germany & India & Japan & Japan \\
\hline Year & 2012 & 2011 & 2006 & 2007 & 2008 & \\
\hline Type of trial & Multicenter & Single center & Multicenter & Single center & Multicenter & Single center \\
\hline
\end{tabular}

ALF: acute liver failure, FHF: fulminant hepatic failure, SH: severe hepatitis, FH: fulminant hepatitis, HE: hepatic encephalopathy, NA: nucleoside analogue, HBV-ALF: acute liver failure due to transient HBV infection, LMV: lamivudine, ETV: entecavir, CS: corticosteroid *Only in case of fulminant hepatitis, **patients fulfilled any 2 of 3 criteria 


\section{HBV-ALF.}

In summary, the present study showed that combination therapy with CS and NA, when administered at a sufficiently early stage, induces the rapid resolution of inflammation and leads to a rapid recovery of the liver function and the prevention of persistent infection in patients with $\mathrm{HBV}$ ALF. The survival rate of the patients who received our combination therapy was superior to that of patients who received NA monotherapy in a recent report by the US-ALF Study Group (4).

We should realize the fact that treatments other than LT must be further investigated for patients in Japan where a shortage of donor livers remains a serious problem. We are convinced that combination therapy in the early stage has a potential survival benefit in HBV-ALF. Further multicenter studies with uniform criteria and treatment protocols are necessary to validate the benefits of the therapy.

\section{Author's disclosure of potential Conflicts of Interest (COI). Naoya Kato: Research funding, BMS and Gilead Japan.}

\section{Financial Support}

This study was supported in part by a Health Labour Sciences Research Grant from the Ministry of Health, Labor and Welfare of Japan as a project by the Intractable Hepato-Biliary Diseases Study Group in Japan.

\section{Acknowledgement}

We are indebted to all our colleagues at the liver units of our hospitals who cared for the patients described herein.

\section{References}

1. Hepatitis B vaccines. Wkly Epidemiol Rec 84: 405-419, 2009.

2. Wai CT, Fontana RJ, Polson J, et al. Clinical outcome and virological characteristics of hepatitis B-related acute liver failure in the United States. J Viral Hepat 12: 192-198, 2005.

3. Yu JW, Sun LJ, Yan BZ, Kang P, Zhao YH. Lamivudine treatment is associated with improved survival in fulminant hepatitis B. Liver Int 31: 499-506, 2011.

4. Dao DY, Seremba E, Ajmera V, et al. Use of nucleoside (tide) analogues in patients with hepatitis B-related acute liver failure. Dig Dis Sci 57: 1349-1357, 2012.

5. Goldstein ST, Zhou F, Hadler SC, Bell BP, Mast EE, Margolis HS. A mathematical model to estimate global hepatitis B disease burden and vaccination impact. Int J Epidemiol 34: 1329-1339, 2005.

6. Escorsell A, Mas A, de la Mata M. Acute liver failure in Spain: analysis of 267 cases. Liver Transpl 13: 1389-1395, 2007.

7. Hadem J, Tacke F, Bruns T, et al. Etiologies and outcomes of acute liver failure in Germany. Clin Gastroenterol Hepatol 10: 664-669. e2, 2012.

8. Oketani M, Ido A, Nakayama N, et al. Etiology and prognosis of fulminant hepatitis and late-onset hepatic failure in Japan: summary of the annual nationwide survey between 2004 and 2009. Hepatol Res 43: 97-105, 2013.

9. Gow PJ, Jones RM, Dobson JL, Angus PW. Etiology and outcome of fulminant hepatic failure managed at an Australian liver transplant unit. J Gastroenterol Hepatol 19: 154-159, 2004.

10. Sako A, Yasunaga H, Horiguchi $\mathrm{H}$, Hashimoto H, Masaki N, Matsuda S. Acute hepatitis B in Japan: incidence, clinical practices and health policy. Hepatol Res 41: 39-45, 2011.

11. Fujiwara K, Mochida S, Matsui A, et al. Fulminant hepatitis and late onset hepatic failure in Japan. Hepatol Res 38: 646-657, 2008.

12. Tillmann HL, Hadem J, Leifeld L, et al. Safety and efficacy of lamivudine in patients with severe acute or fulminant hepatitis B, a multicenter experience. J Viral Hepat 13: 256-263, 2006.

13. Gregory PB, Knauer CM, Kempson RL, Miller R. Steroid therapy in severe viral hepatitis. A double-blind, randomized trial of methyl-prednisolone versus placebo. N Engl J Med 294: 681-687, 1976.

14. Randomized trial of steroid therapy in acute liver failure: a report from the European Association for the Study of the Liver. Gut 20: 620-623, 1979.

15. Rakela J, Mosley JW, Edwards VM, Govindarajan S, Alpert E. A double-blinded, randomized trial of hydrocortisone in acute hepatic failure. Dig Dis Sci 36: 1223-1228, 1991.

16. Yasui S, Fujiwara K, Nakamura M, et al. Virological efficacy of combination therapy with corticosteroid and nucleoside analogue for severe acute exacerbation of chronic hepatitis B. J Viral Hepat 22: 94-102, 2015.

17. Fujiwara K, Hida S, Yasui S, Yokosuka O, Oda S. Corticosteroid might reduce serum levels of pro-inflammatory cytokines in fulminant hepatitis: a case series. Hepatol Res 48: 106-112, 2018.

18. Fujiwara K, Yasui S, Yonemitsu Y, et al. Efficacy of high-dose corticosteroid in the early stage of viral acute liver failure. Hepatol Res 44: 491-501, 2013.

19. Fujiwara $\mathrm{K}$, Yokosuka $\mathrm{O}$, Kojima $\mathrm{H}$, et al. Importance of adequate immunosuppressive therapy for the recovery of patients with "lifethreatening" severe exacerbation of chronic hepatitis B. World J Gastroenterol 11: 1109-1114, 2005.

20. Fujiwara K, Yasui S, Yonemitsu Y, et al. Efficacy of combination therapy of antiviral and immunosuppressive drugs for the treatment of severe acute exacerbation of chronic hepatitis B. J Gastroenterol 43: 711-719, 2008.

21. Fujiwara K, Yasui S, Okitsu K, Yonemitsu Y, Oda S, Yokosuka O. The requirement for a sufficient period of corticosteroid treatment in combination with nucleoside analogue for severe acute exacerbation of chronic hepatitis B. J Gastroenterol 45: 1255-1262, 2010.

22. Mochida S, Takikawa $\mathrm{Y}$, Nakayama N, et al. Classification of the etiologies of acute liver failure in Japan: a report by the Intractable Hepato-Biliary Diseases Study Group of Japan. Hepatol Res 44: 365-367, 2014.

23. Mochida S, Takikawa Y, Nakayama N, et al. Diagnostic criteria of acute liver failure: a report by the Intractable Hepato-Biliary Diseases Study Group of Japan. Hepatol Res 41: 805-812, 2011.

24. Yasui S, Fujiwara K, Tawada A, Fukuda Y, Nakano M, Yokosuka O. Efficacy of intravenous glycyrrhizin in the early stage of acute onset autoimmune hepatitis. Dig Dis Sci 56: 3638-3647, 2011.

25. Iino $S$, Tango $T$, Matsushima $T$, et al. Therapeutic effects of stronger neo-minophagen $\mathrm{C}$ at different doses on chronic hepatitis and liver cirrhosis. Hepatol Res 19: 31-40, 2001.

26. Fujiwara K, Oda S, Abe R, Yokosuka O. On-line hemodiafiltration or high-flow continuous hemodiafiltration is one of the most effective artificial liver support devices for acute liver failure in Japan. J Hepatobiliary Pancreat Sci 22: 246-247, 2015.

27. Reshef R, Sbeit W, Tur-Kaspa R. Lamivudine in the treatment of acute hepatitis B. N Engl J Med 343: 1123-1124, 2000.

28. Schmilovitz-Weiss H, Ben-Ari Z, Sikuler E, et al. Lamivudine treatment for acute severe hepatitis B: a pilot study. Liver Int 24: 547-551, 2004.

29. Kumar M, Satapathy S, Monga R, et al. A randomized controlled trial of lamivudine to treat acute hepatitis B. Hepatology 45: 97101, 2007.

30. Miyake Y, Iwasaki Y, Takaki A, et al. Lamivudine treatment improves the prognosis of fulminant hepatitis B. Intern Med 47: 
1293-1299, 2008.

31. Webster GJ, Reignat S, Maini MK, et al. Incubation phase of acute hepatitis B in man: dynamic of cellular immune mechanisms. Hepatology 32: 1117-1124, 2000.

32. Bernsmeier C, Antoniades CG, Wendon J. What's new in acute liver failure? Intensive Care Med 40: 1545-1548, 2014.

33. Ito $\mathrm{K}$, Yotsuyanagi $\mathrm{H}$, Yatsuhashi $\mathrm{H}$, et al. Risk factors for longterm persistence of serum hepatitis B surface antigen following acute hepatitis B virus infection in Japanese adults. Hepatology 59: 89-97, 2014.

34. Yotsuyanagi H, Ito K, Yamada N, et al. High levels of hepatitis B virus after the onset of disease lead to chronic infection in patients with acute hepatitis B. Clin Infect Dis 57: 935-942, 2013.

35. Yasui S, Fujiwara K, Haga Y, et al. Infectious complications, steroid use and timing for emergency liver transplantation in acute liver failure: analysis in a Japanese center. J Hepatobiliary Pancreat Sci 12: 756-762, 2016.

The Internal Medicine is an Open Access article distributed under the Creative Commons Attribution-NonCommercial-NoDerivatives 4.0 International License. To view the details of this license, please visit (https://creativecommons.org/licenses/ by-nc-nd/4.0/).

(C) 2018 The Japanese Society of Internal Medicine Intern Med 57: 1543-1552, 2018 